\title{
Endoscopic ultrasound-guided rendezvous for access to the right posterior bile duct in a surgical candidate
}

Endoscopic ultrasonography-guided rendezvous technique (EUS-RV) includes two approaches: the intrahepatic and extrahepatic bile duct approaches from the stomach and duodenum, respectively $[1,2]$. However, the technique is impractical when drainage is required for right hepatic bile duct obstruction. Percutaneous transhepatic biliary drainage has a possible risk of tumor seeding in a patient with cholangiocarcinoma; therefore, it is not recommended for surgical candidates [3-5]. We present a case of successful drainage of the obstructed right posterior bile duct using EUS-RV ( Video 1).

A 63-year-old woman was admitted with acute cholangitis. Contrast-enhanced computed tomography revealed Bismuth-Corlette type 4 perihilar cholangiocarcinoma. The surgeons recommended left trisectionectomy. Drainage for the right posterior bile duct was required because the posterior segment of the liver was the future remnant lobe. Transpapillary insertion of the endoscopic nasobiliary drainage tube was attempted. However, this procedure failed, despite the combination of a hydrophilic guidewire and steerable or double-lumen catheter, although biliary cannulation was achieved (> Fig.1). We exchanged the duodenoscope for a linear EUS scope and inserted it into the duodenal bulb. The dilated posterior bile duct was then punctured using a 19-gauge needle ( $>$ Fig. 2 , - Fig.3). A 0.025-inch guidewire was manipulated into the duodenum via the obstruction site and ampulla. The EUS scope was removed with the guidewire left in place. The duodenoscope was reinserted where the EUS-placed guidewire passed from the ampulla. The distal end of the guidewire was grasped with a snare and pulled out through the accessory channel ( $\triangleright$ Fig.4). A catheter was inserted over the guidewire, and finally, a nasobiliary drainage tube was placed in the posterior bile duct ( $\triangleright$ Fig.5). No adverse

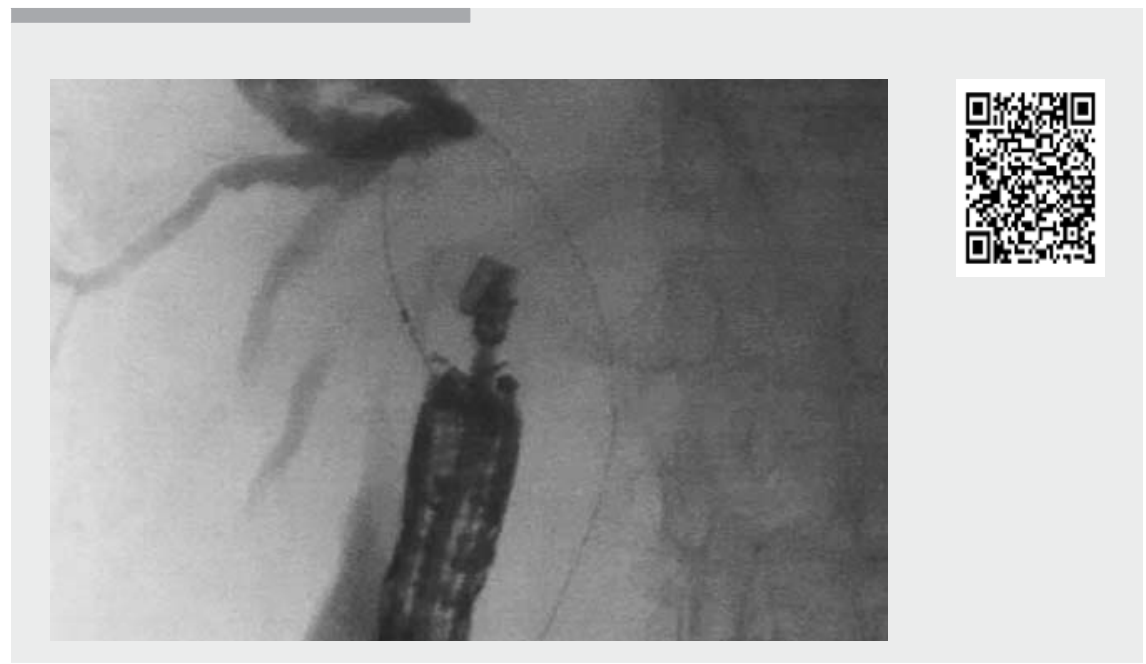

$\checkmark$ Video 1 As drainage of the obstructed right posterior bile duct was impossible using endoscopic retrograde cholangiopancreatography, an endoscopic ultrasonography-guided rendezvous technique was used successfully.

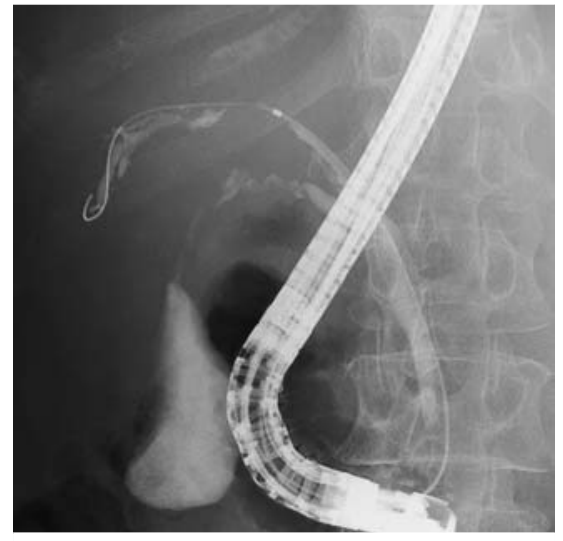

- Fig. 1 Endoscopic retrograde cholangiography demonstrated hilar bile duct obstruction and dilated anterior bile duct. A hydrophilic guidewire could not be introduced into the posterior bile duct despite using a steerable catheter and double-lumen catheter.

event was encountered, and cholangitis and jaundice subsided.

EUS-RV can be useful, especially when drainage for the isolated right hepatic duct is needed in patients scheduled for surgery.

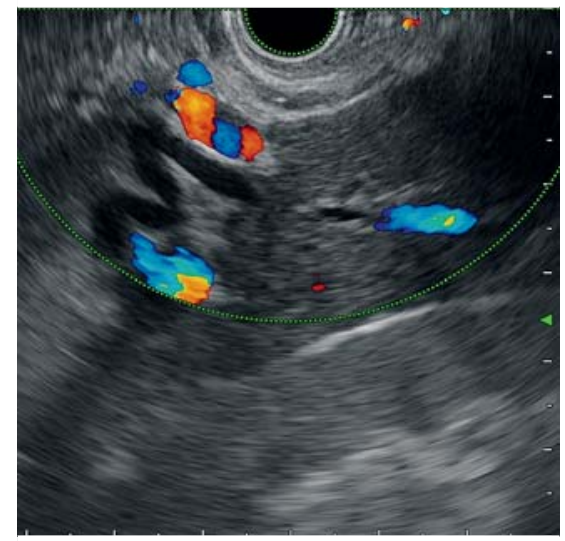

- Fig. 2 Endoscopic ultrasonography scope located at the duodenal bulb showed dilatation of the posterior bile duct.

Endoscopy_UCTN_Code_TTT_1AS_2AD

\section{Competing interests}




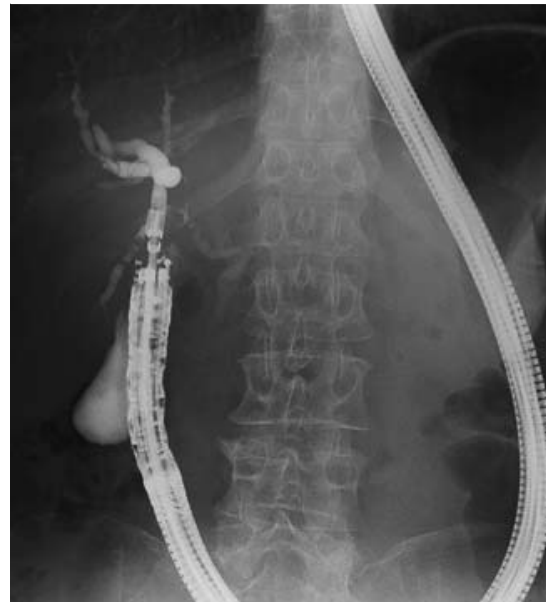

- Fig. 3 Endoscopic ultrasonography (EUS)-guided cholangiography showed dilatation of the posterior duct.

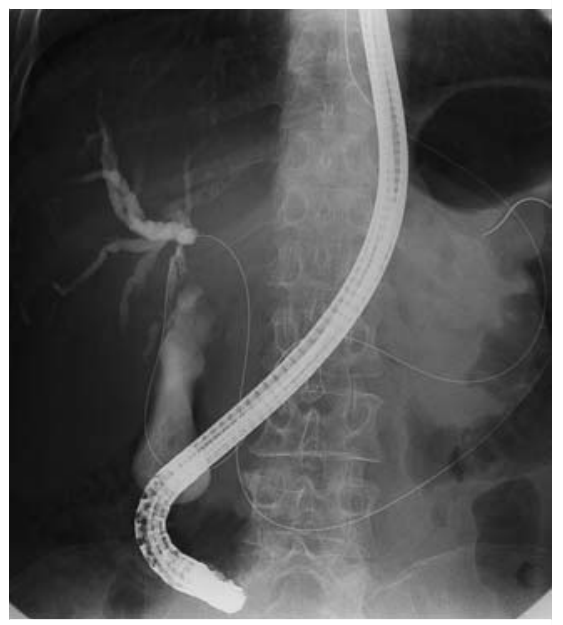

- Fig.4 After a guidewire had been passed in an antegrade manner across the obstruction site and the ampulla into the duodenum, the endoscopic ultrasonography (EUS) scope was exchanged for a duodenoscope, which was introduced alongside the EUS-placed guidewire. The guidewire was retrieved through its accessory channel.

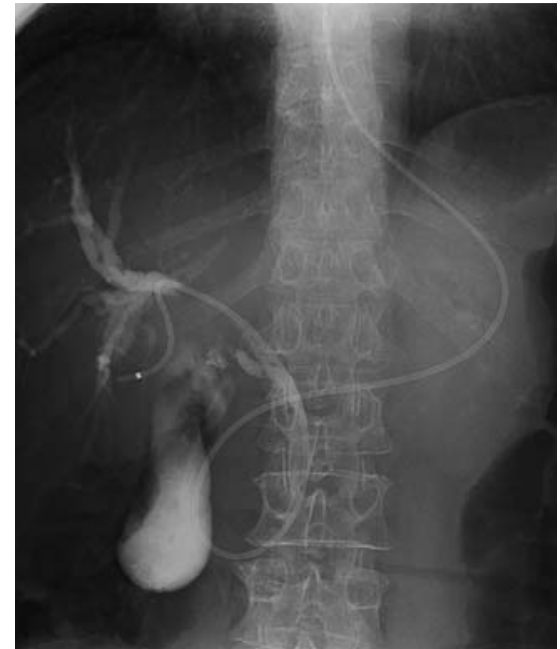

- Fig. 5 A nasobiliary drainage tube was passed over the guidewire and placed in the posterior bile duct.

The authors

Hirotoshi Ishiwatari ${ }^{1}$, Tatsunori Satoh ${ }^{1}$, Junya Sato ${ }^{1}$, Junichi Kaneko ${ }^{1}$, Katsuhisa Ohgi $^{2}$, Hiroyuki Matsubayashi ${ }^{1,3}$, Katsuhiko Uesaka ${ }^{1,2}$

1 Division of Endoscopy, Shizuoka Cancer Center, Shizuoka, Japan

2 Division of Hepato-Biliary-Pancreatic Surgery, Shizuoka Cancer Center, Shizuoka, Japan

3 Division of Genetic Medicine Promotion, Shizuoka Cancer Center, Shizuoka, Japan

\section{Corresponding author}

\section{Hirotoshi Ishiwatari, MD, PhD}

Division of Endoscopy, Shizuoka Cancer Center, 1007 Shimonagakubo Nagaizumicho, Sunto-gun, Shizuoka, Japan

Fax: +81-55-9895551

ishihiro481019@gmail.com

\section{References}

[1] Isayama H, Nakai Y, Itoi T et al. Clinical practice guidelines for safe performance of endoscopic ultrasound/ultrasonographyguided biliary drainage: 2018. J Hepatobiliary Pancreat Sci 2019; 26: 249-269

[2] Iwashita T, Yasuda I, Mukai T et al. EUSguided rendezvous for difficult biliary cannulation using a standardized algorithm: a multicenter prospective pilot study (with videos). Gastrointest Endosc 2016; 83: 394400

[3] Takahashi Y, Nagino M, Nishio H et al. Percutaneous transhepatic biliary drainage catheter tract recurrence in cholangiocarcinoma. Br J Surg 2010; 97: 1860-1866

[4] Yamashita H, Ebata T, Yokoyama Y et al. Pleural dissemination of cholangiocarcinoma caused by percutaneous transhepatic biliary drainage during the management of resectable cholangiocarcinoma. Surgery 2019; 165: 912-917

[5] Miyazaki M, Yoshitomi H, Miyakawa S et al. Clinical practice guidelines for the management of biliary tract cancers 2015: the 2nd English edition. J Hepatobiliary Pancreat Sci 2015; 22: 249-273

\section{Bibliography}

DOI https://doi.org/10.1055/a-1046-1475

Published online: 2.12.2019

Endoscopy 2020; 52: E156-E157

(c) Georg Thieme Verlag KG

Stuttgart · New York

ISSN 0013-726X

\section{ENDOSCOPY E-VIDEOS}

https://eref.thieme.de/e-videos

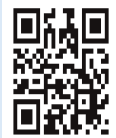

Endoscopy E-Videos is a free access online section, reporting on interesting cases and new techniques in gastroenterological endoscopy. All papers include a high quality video and all contributions are freely accessible online.

This section has its own submission website at

https://mc.manuscriptcentral.com/e-videos 